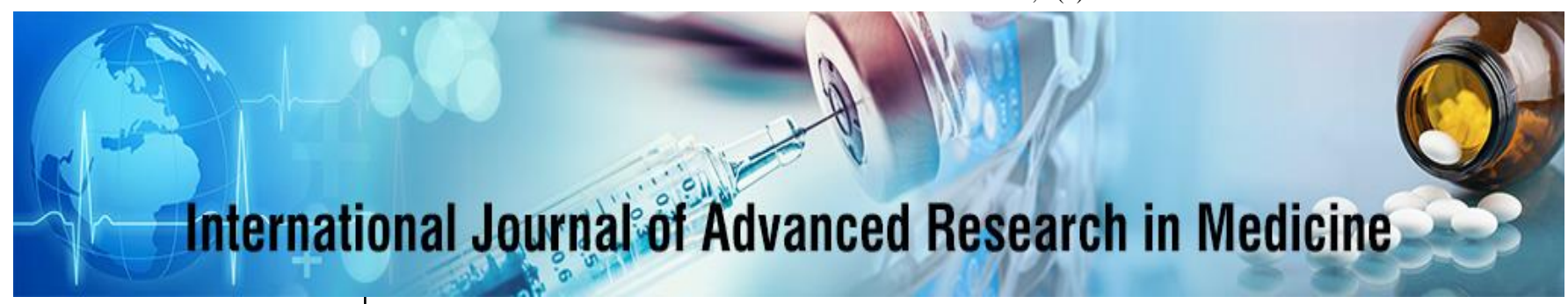

E-ISSN: 2706-9575

P-ISSN: 2706-9567

www.medicinepaper.net/ IJARM 2019; 1(2): 01-03 Received: 02-05-2019

Accepted: 04-06-2019

Vijaya Kumaratunga Department of medicine, Institute of Indigenous Medicine, University in Sri Lanka, Sri Lanka
Corresponding Author: Vijaya Kumaratunga Department of medicine, Institute of Indigenous Medicine, University in Sri Lanka, Sri Lanka

\title{
Assessment of prevalence of cardiovascular risk factors among AMI patients
}

\section{Vijaya Kumaratunga}

\author{
DOI: https://doi.org/10.22271/27069567.2019.v1.i2a.5
}

\begin{abstract}
Background: Among the most common chronic diseases that afflict humans worldwide are diabetes, cardiovascular diseases (CVDs), osteoporosis, arthritis, obesity, chronic obstructive pulmonary disease, inflammatory bowel disease, central nervous system degenerative diseases and some cancers. Hence; the present study was undertaken for assessing the prevalence of cardiovascular risk factors among acute myocardial infarction (AMI) population.

Materials \& Methods: A total of 200 AMI subjects were enrolled in the present study. Complete demographic details of all the patients were obtained. A self-framed questionnaire was given to all the subjects for obtaining the complete medical, clinical and demographic of all the patients. Socioeconomic status was defined on basis of modified Kuppuswamy's Scale, according to which, Socioeconomic classes were divided into upper, middle and lower. Blood samples were obtained from all the patients for assessing the hematological and biochemical profile.

Results: Significant results were obtained while assessing the age-wise correlation of patients. There were 110 males and 90 females in the present study. 33.5 percent of the patients belonged to upper class, while 365 percent of the patients belonged to middle class. 30 percent of the patients belonged to lower class. Significantly higher number of diabetic and hypertensive patients was seen in the present study.

Conclusion: Diabetes, hypertension and increasing age were found to be significant cardiovascular risk factors.
\end{abstract}

Keywords: cardiovascular, risk factors

\section{Introduction}

Chronic diseases have one or more of the following characteristics: they are persistent and leave residual disability; they are caused by non-reversible pathological conditions; and they require special training of the patient on rehabilitation, or may be expected to require prolonged medical supervision, observation or health care. Among the most common chronic diseases that afflict humans worldwide are diabetes, cardiovascular diseases (CVDs), osteoporosis, arthritis, obesity, chronic obstructive pulmonary disease, inflammatory bowel disease, central nervous system degenerative diseases and some cancers ${ }^{[1-3]}$.

An acute myocardial infarction (AMI) is a subset of a spectrum of Ischemic Heart Disease (IHD) that includes unstable angina and AMI with or without ST elevation ${ }^{[4]}$. There are many risk factors for coronary artery disease (CAD) and some can be controlled but not others. The risk factors that can be controlled (modifiable) are: High BP; high blood cholesterol levels; smoking; diabetes; overweight or obesity; lack of physical activity; unhealthy diet and stress ${ }^{[5-8]}$. Some studies have shown the importance of the microenvironment, in particular the family, where genetic influences and lifestyle are equally important. Hence; under the light of above mentioned data, the present study was undertaken for assessing the prevalence of cardiovascular risk factors among known population.

\section{Materials and Methods}

The present study was conducted in the department of internal medicine of the medical institute and it included assessment of prevalence of cardiovascular risk factors among known population. Ethical approval was obtained from institutional ethical committee and written consent from all the patients after explaining in detail the entire research protocol. A total of 200 AMI subjects were enrolled in the present study. Complete demographic details of all the patients were obtained. A self-framed questionnaire was given to all the subjects for obtaining the complete medical, clinical and demographic of all the patients. Socio- 
economic status was defined on basis of modified Kuppuswamy's Scale, according to which,

Socio-economic classes were divided into upper, middle and lower ${ }^{[9]}$. Blood samples were obtained from all the patients for assessing the hematological and biochemical profile. All the results were recorded in Microsoft excel sheet and were assessed by SPSS software. Chi- square test was used for assessment of level of significance. P- value of less than 0.05 was taken as significant.

\section{Results}

In the present study, a total of 200 AMI patients were enrolled in the present study. Mean age of the patients of the present study was 59.4 years. 54 percent of the patients belonged to the age group of more than 45 years. Significant results were obtained while assessing the age-wise correlation of patients. There were 110 males and 90 females in the present study. 33.5 percent of the patients belonged to upper class, while 365 percent of the patients belonged to middle class. 30 percent of the patients belonged to lower class. Significantly higher number of diabetic and hypertensive patients was seen in the present study.

\section{Discussion}

Cardiovascular diseases (CVDs) account for the greatest burden of morbidity and mortality worldwide in both developed and developing countries. Coronary heart disease (CHD) is the greatest contributor to CVD and risk factors such as cigarette smoking, elevated cholesterol levels, high blood glucose, high blood pressure, physical inactivity and obesity are the driving forces behind the disease burden. Over $90 \%$ of CHD events occur in individuals with at least 1 risk factor ${ }^{[7-9]}$

In the present study, a total of 200 AMI patients were enrolled in the present study. Mean age of the patients of the present study was 59.4 years. 54 percent of the patients belonged to the age group of more than 45 years. Significant results were obtained while assessing the age-wise correlation of patients. Nangia $\mathrm{R}$ et al. assessed the prevalence of raised BMI, blood pressure, cholesterol and blood sugar among serving armed forces personnel $\geq 35 \mathrm{yrs}$ of age. The study was carried out between Jan 2013-Jun 2013. The study included all individuals $\geq 35$ yrs of age deployed/posted in specific districts of northern part of the country $(\mathrm{N}=5143)$ instead of a limited sample size. In this study, obesity was observed in $3.42 \%$, raised BP in $14.07 \%$ and raised blood sugar levels in $1.71 \%$. Additionally, $67.72 \%$ were pre-obese and $82.65 \%$ were pre-hypertensives. Lower prevalence of hypertension, hyperglycemia and dyslipidemia was observed in armed forces personnel in comparison to country specific data ${ }^{[10]}$.

In the present study, there were 110 males and 90 females in the present study. 33.5 percent of the patients belonged to upper class, while 365 percent of the patients belonged to middle class. 30 percent of the patients belonged to lower class. Khetan A et al. assessed the prevalence and pattern of cardiovascular risk factors in a population in India. This is a cross-sectional study from Project SEHAT (Study to Enhance Heart Associated Treatments), an ongoing cluster randomised controlled trial testing the hypothesis that a community health worker-led intervention can improve the control of cardiovascular risk factors in a community in
West Bengal, India. For the baseline data, 3556 adults, between the ages of 35 and 70, were screened for hypertension, diabetes and smoking. For hypertension and diabetes, an elevated reading was confirmed on a repeat visit. $18.3 \%(n=650), 9.0 \%(n=317)$ and $14.1 \%(n=500)$ of adults were diagnosed with hypertension, diabetes and smoking, respectively. In their population in semiurban India, one in three adults has a major cardiovascular risk factor, with low control rates ${ }^{[11]}$.

In the present study, significantly higher number of diabetic and hypertensive patients was seen. Gikas A et al. assessed the current prevalence of self-reported risk factors and CHD in Greek adult population. The study sample included 2636 subjects (men, 49.5\%; mean age, 50.5; range 20-95 years), with similar age and sex distribution to the target population. The age-standardized prevalence rates of five major risk factors were as follows: type 2 diabetes $11.1 \%$, hypercholesterolemia (cholesterol $>240 \mathrm{mg} / \mathrm{dl}$ or using cholesterol-lowering medication) $23.8 \%$, hypertension $27.2 \%$, current smoking $38.9 \%$ and physical inactivity $43 \%$. Of the participants, only $21 \%$ were free of any of these factors. Classic risk factors are highly prevalent and frequently clustered; especially in adults aged 50 years and older $^{[12]}$.

Table 1: Age-wise distribution of patients

\begin{tabular}{|c|c|c|c|}
\hline $\begin{array}{c}\text { Age group } \\
\text { (years) }\end{array}$ & $\begin{array}{c}\text { Number of } \\
\text { patients }\end{array}$ & $\begin{array}{c}\text { Percentage } \\
\text { of patients }\end{array}$ & $\begin{array}{c}\text { p- } \\
\text { value }\end{array}$ \\
\hline Less than 25 & 20 & 10 & \multirow{2}{*}{0.00} \\
\hline 25 to 45 & 72 & 36 & (Significant) \\
\hline More than 45 & 108 & 54 & (S) \\
\hline
\end{tabular}

Table 2: Gender-wise distribution of patients

\begin{tabular}{|c|c|c|c|}
\hline Gender & $\begin{array}{c}\text { Number of } \\
\text { patients }\end{array}$ & $\begin{array}{c}\text { Percentage of } \\
\text { patients }\end{array}$ & $\begin{array}{c}\text { p- } \\
\text { value }\end{array}$ \\
\hline Males & 110 & 55 & \multirow{2}{*}{0.15} \\
\hline Females & 90 & 45 & \\
\hline
\end{tabular}

Table 3: Distribution of patients

\begin{tabular}{|c|c|c|c|}
\hline $\begin{array}{c}\text { Socio-economic } \\
\text { status }\end{array}$ & $\begin{array}{c}\text { Number of } \\
\text { patients }\end{array}$ & $\begin{array}{c}\text { Percentage } \\
\text { of patients }\end{array}$ & $\begin{array}{c}\text { p- } \\
\text { value }\end{array}$ \\
\hline Upper & 67 & 33.5 & \multirow{2}{*}{0.41} \\
\hline Middle & 73 & 36.5 & \multirow{2}{*}{0.41} \\
\hline Lower & 60 & 30 & \\
\hline
\end{tabular}

Table 4: Distribution of patients according to residence

\begin{tabular}{|c|c|c|c|}
\hline Residence & $\begin{array}{c}\text { Number of } \\
\text { patients }\end{array}$ & $\begin{array}{c}\text { Percentage of } \\
\text { patients }\end{array}$ & $\begin{array}{c}\text { p- } \\
\text { value }\end{array}$ \\
\hline Rural & 112 & 56 & \multirow{2}{*}{0.82} \\
\hline Urban & 88 & 44 & \\
\hline
\end{tabular}

Table 5: Distribution of patients according to diabetes

\begin{tabular}{|c|c|c|c|}
\hline Diabetes & $\begin{array}{c}\text { Number of } \\
\text { patients }\end{array}$ & $\begin{array}{c}\text { Percentage of } \\
\text { patients }\end{array}$ & $\begin{array}{c}\text { p- } \\
\text { value }\end{array}$ \\
\hline Present & 128 & 64 & 0.00 \\
Absent & 72 & 36 & (Significant) \\
\hline
\end{tabular}

Table 5: Distribution of patients according to Hypertension

\begin{tabular}{|c|c|c|c|}
\hline Hypertension & $\begin{array}{c}\text { Number of } \\
\text { patients }\end{array}$ & $\begin{array}{c}\text { Percentage of } \\
\text { patients }\end{array}$ & $\begin{array}{c}\text { p- } \\
\text { value }\end{array}$ \\
\hline Present & 144 & 72 & 0.00 \\
Absent & 56 & 28 & (Significant) \\
\hline
\end{tabular}




\section{Conclusion}

Under the light of above obtained results, the authors conclude that diabetes, hypertension and increasing age were found to be significant cardiovascular risk factors. However; further studies are recommended.

\section{References}

1. Chadha SL, Radhakrishnan S, Ramachandran K, Kaul U, Gopinath N. Indian J Med Res. 1990; 92:423-430.

2. Prabhakaran D, Shah Pankaj, Chaturvedi V, Ramakrishnan L, Manhapra A, Reddy KS. Cardiovascular risk factor prevalence among men in a large industry of north India. Natl Med J India. 2005; 18:59-65.

3. Coronary heart disease and risk factors in India - on the brink of an epidemic? Indian Heart J. 2012; 64(4):3647.

4. Raman Kutty V, Balakrishnan KG, Jayasree AK, Thomas Jessy. Prevalence of coronary heart disease in the rural population of Thiruvananthapuram district, Kerala, India. Int J Cardiol. 1993; 39:59-70.

5. Chadha SL, Gopinath N, Shekhawat S. Urban-rural differences in the prevalence of coronary heart disease and its risk factors in Delhi. Bull World Health Organ. 1997; 75(1):31-38.

6. Singh RB, Sharma JP, Rastogi V. Prevalence of coronary artery disease and coronary risk factors in rural and urban populations of north India. Eur Heart J. 1997; 18:1728-1735.

7. Mansur ADP, Mattar APL, Rolim AL, Yoshi FR, Marin JFG, César LAM et al. Distribution of risk factors in parents and siblings of patients with early coronary artery disease. Arq. Bras. Cardiol. São Paulo. 2003; 80:6.

8. Zöller B1, Li X, Sundquist J, Sundquist K. Multiplex sibling history of coronary heart disease is a strong risk factor for coronary heart disease. Eur Heart J. 2012; 33(22):2849-55.

9. Wani RT. Socioeconomic status scales-modified Kuppuswamy and Udai Pareekh's scale updated for 2019. J Family Med Prim Care. 2019; 8(6):1846-1849. doi:10.4103/jfmpc.jfmpc_288_19

10. Nangia $R$, Singh $H$, Kaur $K$. Prevalence of cardiovascular disease (CVD) risk factors. Med J Armed Forces India. 2016; 72(4):315-319.

11. Khetan A, Zullo M, Hejjaji V et al. Prevalence and pattern of cardiovascular risk factors in a population in India. Heart Asia. 2017; 9(2):e010931.

12. Gikas A et al. Prevalence of Major Cardiovascular Risk Factors and Coronary Heart Disease in a Sample of Greek Adults: The Saronikos Study. Open Cardiovasc Med J. 2016; 10:69-80. 